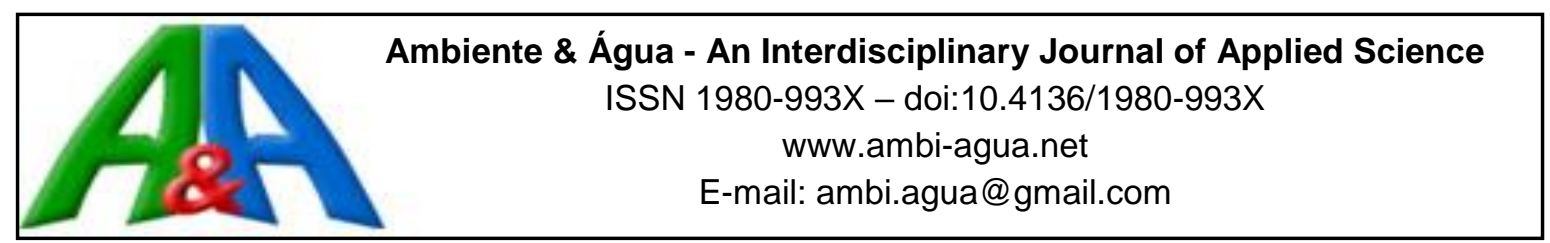

\title{
Estatística espacial para avaliar a relação entre saneamento básico, IDH e remanescente de cobertura vegetal no estado de Goiás, Brasil
}

\author{
doi:10.4136/ambi-agua.1825 \\ Received: 14 Dec. 2015; Accepted: 11 May 2016 \\ Saulo Bruno Silveira e Souza*; Nilson Clementino Ferreira; \\ Klebber Teodomiro Martins Formiga \\ Universidade Federal de Goiás (UFG), Goiânia, GO, Brasil \\ Escola de Engenharia Civil e Ambiental \\ *Autor correspondente: e-mail: saulobruno@ hotmail.com, \\ nclferreira@gmail.com,klebber.formiga@gmail.com
}

\section{RESUMO}

Neste trabalho buscou-se estabelecer uma relação proveniente das análises espaciais de agrupamentos dos 246 municípios do estado de Goiás, Brasil, considerando os dados de saneamento básico, índice de desenvolvimento humano e cobertura vegetal. Os dados de E. coli, turbidez e cor aparente de 140 mananciais goianos também foram coletados mensalmente entre 2005 e 2009 e comparados com a cobertura vegetal e o regime de precipitação. Para a elaboração de análises espaciais de agrupamento, utilizou-se o índice de Getis-Ord, aplicado aos dados de saneamento, IDH e índice de cobertura vegetal (imagens Landsat7 ETM+ obtidas em 2002). Notou-se uma forte correlação ( $<<0,05)$ entre as áreas que possuem maior índice de saneamento com as regiões que tem maior IDH, e relação inversa com o índice de remanescente vegetal. Foi possível observar a alteração da qualidade da água dentre os municípios que possuem maior intervenção e modificação do meio ambiente, sendo que o Norte Goiano, que possui maior remanescente vegetal, apresentou um dos melhores valores para cor aparente, turbidez e E. coli, dentre os demais municípios. Ainda, foi observada elevação nas concentrações destes parâmetros, influenciada pela precipitação, que no estado de Goiás, Brasil, ocorrem primordialmente nos meses de novembro a abril.

Palavras-chave: degradação ambiental, recursos hídricos, vegetação ripária.

\section{Spatial statistics to evaluate the relationship between basic sanitation, HDI and remnant vegetation in the State of Goiás, Brazil}

\section{ABSTRACT}

This study presents the results of the spatial clustering of the 246 towns of the State of Goiás, Brazil, considering basic sanitation data, human development index and land use. Monthly data related to E. coli, turbidity and apparent color from 140 local sources between 2005 and 2009 were also analyzed and compared with the vegetation cover and precipitation. For the preparation of spatial clustering analysis, the Getis-Ord index was used and it was applied to sanitation, Human Development Index (HDI) and vegetation cover index 
(Landsat 7 ETM+ images acquired in 2002). It was observed that there is a strong correlation $(\mathrm{p}<0.05)$ between areas that have higher rates of sanitation with the regions that have the highest HDI levels, and an inverse relationship with the occurrence of remaining vegetation cover index. There was a change in water quality among towns that have greater intervention in land use, especially in the North of Goiás, Brazil, which has the largest remaining vegetation areas and showed better values for apparent color, turbidity and E. coli than the other municipalities. In addition, concentrations of these parameters increased with rainfall, which in the State of Goiás, Brazil, occurs primarily between November and April.

Keywords: environmental degradation, riparian vegetation, water resources.

\section{INTRODUÇÃO}

A contaminação das águas no meio natural representa um dos principais riscos à saúde pública. Existe uma estreita correlação entre a qualidade de água e as inúmeras enfermidades que acometem as populações, especialmente aquelas não atendidas por serviços de saneamento (Prüss-Üstünet al., 2008; Prüss-Üstüne e Corvalán, 2006; Hutton e Haller, 2004; SIWI e WHO, 2005). Prüss-Üstünet al. (2008) estimam que cerca de $4 \%$ das mortes no mundo se devem a doenças de veiculação hídrica devido à falta de saneamento. Conforme Briscoe (1985), em simulações com dados demográficos de 1816 a 1905 de Lyon na França, notou-se que as intervenções ambientais previnem mortes e elevam a expectativa de vida em sete vezes mais que as iniciativas de natureza biomédica. $\mathrm{O}$ referido autor postula que, em curto prazo, o efeito mensurável do abastecimento de água e do esgotamento sanitário pode parecer reduzido, pela reposta não linear da intervenção, mas a longo prazo seu efeito sobre a saúde é substancialmente superior ao de intervenções médicas.

A relação das condições de saneamento com o meio ambiente e com o quadro epidemiológico é reconhecida pelos legisladores brasileiros. Tais condições constam como alguns dos fatores determinantes para a saúde pública, art. $3^{\circ}$ da Lei 8.080/90 - que dispõe sobre a prestação dos serviços de saúde no País. O abastecimento de água, o esgotamento sanitário, a coleta dos resíduos sólidos e o manejo da drenagem urbana, considerando a ocupação urbana da bacia, são vitais para a melhoria das condições de vida e saúde das comunidades. São também preponderantes na recuperação e proteção do meio ambiente, que é uma exigência da Lei Federal 12.651/2012, o que consagra a necessidade de sua universalização, já prevista na Lei Federal 11.445/2007.

Um fator impactante sobre a qualidade dos recursos hídricos é a forma como o homem se apropria e usa o solo. Frequentemente, a perda de qualidade da água se deve à falta de planejamento e gestão das bacias hidrográficas. Tal realidade se materializa no uso indiscriminado dos recursos hídricos, no desmatamento de nascentes e na poluição dos rios e lagos. Inúmeros pesquisadores têm monitorado a perda de qualidade da água em função da ocupação desenfreada e desordenada da bacia (Walton e Hunter, 2008; 2009; Bonnet et al., 2008; Toledo e Nicolella, 2002; Boyer et al., 2002; Rhodes et al., 2001). Rabelo et al. (2009) monitoraram a qualidade da água em duas bacias do bioma Cerrado, constatando o impacto do uso da terra intenso sobre a qualidade da água. Estes pesquisadores ressaltaram a necessidade da preservação da vegetação nativa (principalmente ao longo dos rios e das nascentes).

Logo, para se alcançar bons índices de qualidade de vida e de desenvolvimento econômico, é necessário a preconização e execução de um plano de ocupação da bacia hidrográfica de maneira clara, objetiva e eficaz, associado à implementação de políticas de saneamento. Assim, poder-se-á ter um menor impacto do uso e ocupação da bacia, resguardando a vegetação ciliar. Estaria, assim, garantida uma melhor qualidade da água em 
meio natural, bem como serviços de abastecimento de água, esgotamento sanitário, coleta dos resíduos sólidos e manejo da drenagem urbana. Isto, sem descurar da devida proteção ao meio ambiente, e desta forma poder alcançar um desenvolvimento mais sustentado e equilibrado.

A principal hipótese é que os locais no estado de Goiás, onde ocorrem os maiores índices de desenvolvimento humano, coincidem com aqueles em que existe maior disponibilidade de saneamento básico. No entanto são regiões de intensa ocupação, com bacias hidrográficas contendo pouca vegetação nativa e que apresentam mananciais com qualidade de água inferior.

Neste trabalho busca-se estabelecer uma relação proveniente das análises espaciais de agrupamentos dos 246 municípios do Estado de Goiás, considerando os dados de saneamento básico, índice de desenvolvimento humano e remanescente de cobertura vegetal, bem como os dados de E. coli, turbidez e cor aparente de 140 mananciais goianos. Também foram estabelecidas relações entre estas variáveis com os meses com maior precipitação, bem como uma análise da variação temporal dos valores observados, relacionando com a resolução CONAMA 357/2005.

\section{CARACTERIZAÇÃO DA ÁREA DE ESTUDO}

A área de estudo é o estado de Goiás, o qual se localiza na região centro-oeste do Brasil, entre as longitudes $53^{\circ} 14^{\prime} 52^{\prime \prime} \mathrm{W}$ e $45^{\circ} 54^{\prime} 23^{\prime \prime} \mathrm{W}$ e entre as latitudes $12^{\circ} 23^{\prime} 44^{\prime \prime} \mathrm{S}$ e $19^{\circ} 28^{\prime} 58^{\prime \prime} \mathrm{S}$.

Em relação ao Índice de Desenvolvimento Humano (IDH), até o ano 2000 o Estado de Goiás estava em $8^{\circ}$ lugar no Brasil, com 0,776. Goiás está dividido em 246 municípios, agrupados em cinco grandes mesorregiões. Este Estado se destaca no Brasil pelo seu significante/importante incremento demográfico. Em 2000, a população era de 4.514 .510 habitantes e em 2010 chegou a 5.664.749 habitantes (IBGE, 2011), ou seja, um aumento populacional de $25,5 \%$. A população goiana está concentrada principalmente na mesorregião Centro Goiana, onde residem $51,0 \%$ dos habitantes. Essa concentração é explicada principalmente pela localização da capital do Estado que forma com mais dezenove municípios a Região Metropolitana de Goiânia.

No Sul Goiano, residem 21,3\% da população, e nessa mesorregião se destacam os municípios de Rio Verde, Jataí, Mineiros, Chapadão do Céu e Catalão. A concentração populacional nela registrada foi "induzida" principalmente pelo significante desenvolvimento do agronegócio.

A mesorregião denominada Leste Goiano concentra $18,9 \%$ da população, devido à proximidade da Capital Federal. Os municípios mais populosos são os localizados no entorno de Brasília/DF, tais como Cristalina, Luziânia, Planaltina, Formosa, Águas Lindas de Goiás. É importante mencionar que tais municípios tiveram um importante incremento populacional nas últimas décadas, que resultaram em vários problemas sociais, falta de saneamento básico e deficiente infraestrutura de saúde, educação, segurança e transporte. As mesorregiões Norte Goiano e Noroeste Goiano são as menos populosas do Estado. Nelas se concentram, respectivamente, $4,9 \%$ e 3,8\% da população estadual (IBGE, 2011).

A intensa ocupação do estado de Goiás resultou na remoção da cobertura vegetal autóctone de extensas áreas para a formação de pastagens e áreas agrícolas. De acordo com mapeamento do uso do solo realizado a partir de imagens Landsat7 ETM+ obtidas em 2002, as áreas agrícolas ocupavam 18,1\%, enquanto que as pastagens ocupavam 45,0\% do território goiano. As manchas urbanas e os grandes corpos d'água ocupavam pouco mais de $1,3 \%$ do Estado, restando, portanto $35,7 \%$ da superfície do solo que estaria coberta pela vegetação nativa (Sano et al., 2008). 


\section{MATERIAL E MÉTODOS}

Este trabalho foi elaborado a partir da organização de uma extensa base de dados geográficos do estado de Goiás. Além disso, foram compilados dados oriundos da Empresa de Saneamento de Goiás (SANEAGO), acerca da qualidade da água captada em cento e quarenta municípios goianos.

Para a avaliação dos resultados de qualidade da água, selecionaram-se os parâmetros cor aparente, turbidez e E. coli. Outros parâmetros foram avaliados, porém não possuíam representatividade temporal. Estes elementos tiveram amostras coletadas mensalmente durante os anos de 2005 a 2009, mensurados conforme recomendações no "Standard Methods for the Examination of Water and Wastewater" (APHA et al., 2005). Tais indicadores foram selecionados por terem sido monitorados em todos os 140 mananciais. Pesou, ainda, o fato de serem relevantes como paradigmas da qualidade da água e serem sensíveis às alterações e modificações das bacias hidrográficas (Libânio et al., 2005).

A turbidez pode indicar, principalmente, problemas relacionados à erosão dos solos nas áreas circunvizinhas aos cursos d'água. $\mathrm{O}$ aumento da turbidez pode provocar impactos, pois reduz a fotossíntese da vegetação enraizada submersa e algas. Além disso, pode exigir manobras operacionais nas estações de tratamento de água, por meio de alterações nas dosagens de coagulantes.

A determinação da E. coli assume importância como parâmetro indicador da possibilidade da existência de micro-organismos patogênicos responsáveis pela transmissão de doenças de veiculação hídrica, tais como febre tifóide, febre paratifóide, disenteria bacilar e cólera (Libânio et al., 2005).

A base de dados geográficos foi sistematizada a partir da interação entre dados de saneamento básico obtidos para todos os municípios brasileiros durante os levantamentos censitários realizados nos anos 2000 e 2010 (IBGE, 2011). Neste trabalho, foram considerados somente os municípios do estado de Goiás. Os dados de saneamento básico utilizados são resultados da compilação elaborada pelo Instituto Brasileiro de Geografia e Estatística (IBGE), a partir dos dados obtidos nos censos, publicados em 2011. Para cada município, foi calculada a porcentagem de domicílios com serviços adequados de saneamento. Enquadram-se nesta categoria os domicílios ligados à rede pública de água tratada, à rede de esgotamento sanitário e com coleta de lixo. Da mesma forma, foi obtida para cada município a porcentagem de domicílios que conta com serviço de saneamento semiadequado, ou seja, os que não contam com os três tipos de serviços (água, esgoto e coleta de lixo), mas que contam com pelo menos um dos serviços. Finalmente, está disponível nos dados de saneamento a porcentagem de domicílios em cada município goiano, em que o serviço de saneamento é inadequado. Esses últimos não contam com qualquer serviço de saneamento (rede de água tratada, esgotamento sanitário e coleta de lixo).

Com o intuito de avaliar a situação social dos municípios goianos, foi utilizado o IDH, que é uma medida comparativa onde são atribuídos valores que variam de zero (baixo índice) a um (alto índice). O IDH é elaborado a partir de dados de expectativa de vida ao nascer (saúde, longevidade), educação e PIB per capita (como um indicador de renda) recolhidos a nível nacional. As três dimensões contempladas pelo IDH (expectativa de vida, educação e renda), apresentam grande relação com o nível de saneamento dos municípios, uma vez que este induz melhorias nas três variáveis do IDH. No entanto, o IDH não considera a qualidade ambiental dos municípios, e essa é uma grande lacuna quando se trata de saneamento. Com efeito, em municípios com saneamento adequado a macro drenagem pode estar comprometida devido à intensidade do uso e ocupação do solo com extermínio da vegetação nativa.

Os remanescentes de vegetação nativa disponível nos municípios goianos, foram avaliados a partir do mapeamento do uso e ocupação do solo do estado de Goiás, na escala 
1:250.000. Esta base cartográfica foi elaborada, no âmbito do projeto "Identificação de Áreas Prioritárias para Conservação da Biodiversidade no estado de Goiás”. Utilizou-se, ainda, a interpretação de imagens Landsat 7 ETM+ de 2001/2002, compilação de informações do projeto RadamBrasil e reconhecimento de campo (Sano et al., 2008).

De posse da base de dados organizada, deu-se início à elaboração de análises espaciais de agrupamento, utilizando o índice de Getis-Ord (Equações 1,2,3), a partir do qual se avalia uma variável quantitativa em uma área, considerando o contexto das áreas vizinhas.

$$
G_{i}^{*}=\frac{\sum_{j=1}^{n} w_{i, j} x_{j}-\bar{X} \sum_{j=1}^{n} w_{i, j}}{\sqrt[S]{\frac{\left[n \sum_{j=1}^{n} w_{i, j}^{2}-\left(\sum_{j=1}^{n} w_{i, j}\right)^{2}\right]}{n-1}}} \quad S=\sqrt{\frac{\sum_{j=1}^{n} x_{j}^{2}}{n}-(\bar{X})^{2}} \quad \bar{X}=\frac{\sum_{j=1}^{n} x_{j}}{n}
$$

em que:

$\mathrm{G}_{\mathrm{i}}{ }^{*}=$ índice de Getis-Ord;

$\mathrm{S}=$ desvio padrão, $\bar{X}=$ média da variável;

$\mathrm{x}_{\mathrm{j}}$ é o valor da variável quantitativa do município $\mathrm{j}$;

$\mathrm{W}_{\mathrm{i}, \mathrm{j}}$ é o peso espacial entre os municípios i; e

j, n é o número total de municípios.

O índice de Getis-Ord foi aplicado sobre as variáveis de saneamento adequado e remanescente de vegetação nativa, e em uma segunda etapa, sobre as regiões de alta, baixa e média ocorrência de saneamento adequado e vegetação nativa. Assim, foram obtidos valores concernentes ao IDH.

\section{RESULTADOS E DISCUSSÃO}

O saneamento básico do estado de Goiás atende de forma adequada apenas uma pequena parcela dos domicílios goianos. Em levantamentos censitários realizados nos anos de 2000 e 2010, o IBGE agrupou as informações de saneamento básico em três categorias: Categoria 1saneamento adequado (quando o domicílio é atendido pela coleta de lixo e está conectado nas redes de distribuição de água e coleta de esgoto). Categoria 2- saneamento semiadequado (quando o domicílio dispõe de pelo menos um serviço). Categoria 3 - saneamento inadequado, quando o domicílio não dispõe de qualquer tipo de serviço de saneamento (IBGE, 2011). Na Figura 1 é possível observar a evolução do Saneamento Básico em Goiás em 2000 e 2010.

Conforme Figura 1, no ano de 2000, 11,1\% dos domicílios goianos contavam com saneamento básico adequado. Em 2010 houve um acréscimo considerável de 99,8\%, e assim $22,1 \%$ dos domicílios passaram a lograr de tal situação. Enquanto isso, saneamento básico semiadequado, que atende a maioria dos domicílios, sofreu uma pequena queda de $2,7 \%$ indo de $63,2 \%$ para $60,5 \%$. O saneamento básico inadequado também sofreu uma queda significativa de $8,6 \%$ no período do levantamento, indo de $26,0 \%$ para $17,4 \%$ dos domicílios goianos sem qualquer tipo de saneamento básico.

A partir de análises de agrupamentos utilizando o índice Getis-Ord, para a variável porcentagem de domicílios com serviços de saneamento adequado, foi possível observar que a região sul do estado de Goiás concentra os municípios mais privilegiados. As regiões norte e central concentram os municípios que menos dispõem desse tipo de serviço, ou seja, municípios onde apenas uma minoria dos domicílios é beneficiada. Na região central do Estado, estão os municípios onde ocorre grande desigualdade em relação à oferta de saneamento adequado aos domicílios, conforme apresentado na Figura 2. Observa-se ainda 
que, após uma década de investimentos, as diferenças regionais nos serviços de saneamento não se alteraram.

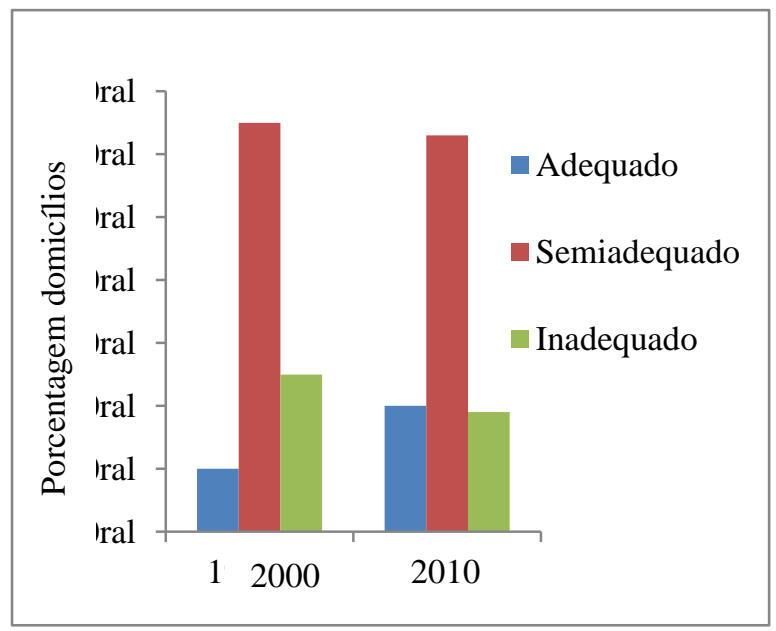

Figura 1. Evolução do saneamento básico em Goiás do ano 2000 para 2010.

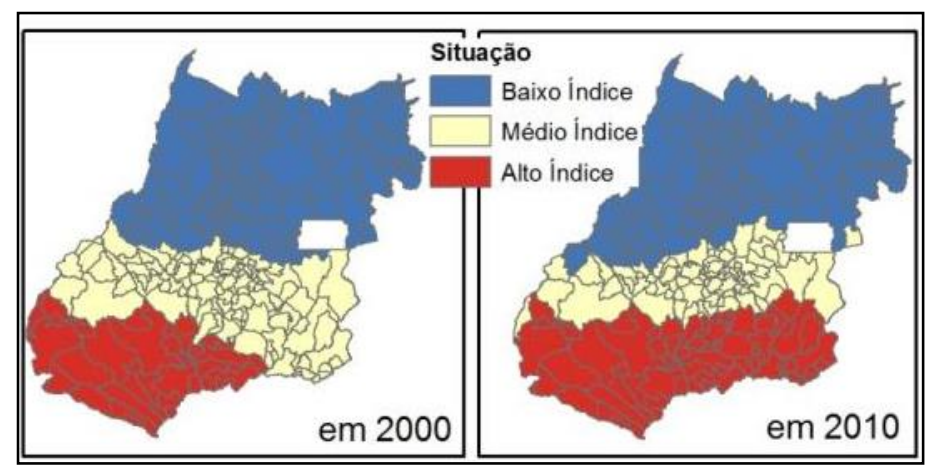

Figura 2. Índices de disponibilização de serviço de saneamento básico adequado nos municípios em 2000 e 2010.

As diferenças regionais não tiveram alterações, de maneira significante, quando se avalia a porcentagem de domicílios com saneamento adequado em 2000 e 2010 nas três regiões mapeadas na Figura 2. No entanto, é possível constatar significativos aumentos da oferta desses serviços (Figura 3). Em 2000, na região sul do Estado (área vermelha), em média $21,2 \%$ dos domicílios contavam com saneamento adequado. Uma década depois $39,7 \%$ dos domicílios passaram a contar com esse tipo de serviço, tendo-se um incremento, portanto, de 18,49\%. Na região de índice de agrupamento médio (região central de Goiás), apenas 10,0\% dos domicílios contavam com saneamento adequado em 2000. No ano de 2010, esse valor passou para $21,6 \%$, um incremento de $11,6 \%$. Finalmente, na parte norte o incremento na porcentagem de municípios com saneamento adequado foi de $12,7 \%$, passando de $4,9 \%$ dos domicílios em 2000, para 17,6\% em 2010.

Observa-se que a região em que existe maior quantidade de domicílios com saneamento adequado, também possui maior IDH (Figura 4). Valores menores são registrados nas regiões com evidentes carências de saneamento adequado. Tal relação também foi observada por Libânio et al. (2005), que avaliaram 127 países, além dos estados brasileiros, constatando a correlação entre os índices de IDH e de saneamento para dados de 2000. 


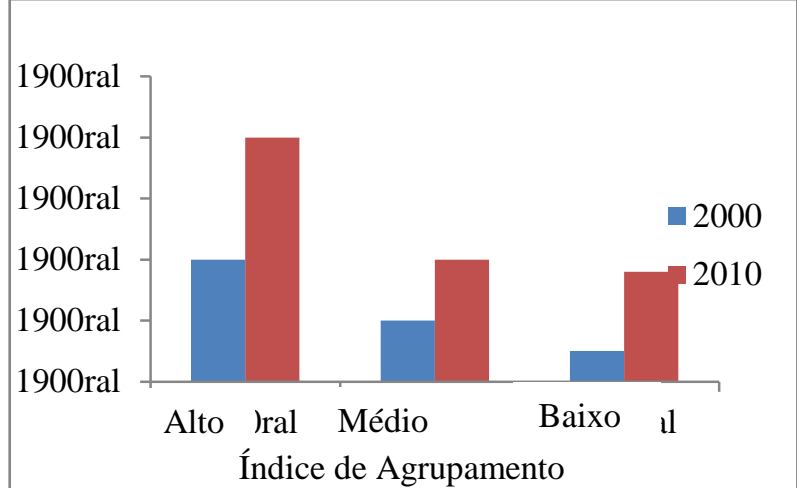

Figura 3. Porcentagem dos domicílios atendidos com saneamento básico adequado nos anos de 2000 e 2010, conforme o mapeamento de agrupamento.

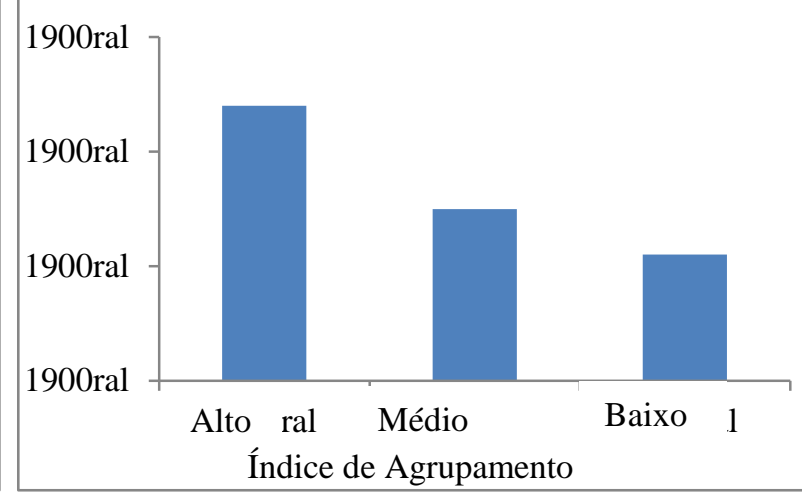

Figura 4. Índice de desenvolvimento humano nos agrupamentos de municípios com saneamento adequado em 2010.

A clara correlação entre o IDH e a abrangência dos serviços de saneamento básico pode ser explicada pelo fato de o cálculo desse índice levar em consideração a expectativa de vida ao nascer. Essa expectativa é um importante indicador de saúde e retrata, em certo grau, as condições de saneamento. Tal parâmetro, associado às estatísticas de renda e de educação da população e de preservação do meio ambiente, constitui os fundamentos que formatam o IDH.

$\mathrm{Na}$ Figura 5 nota-se que na região sul do Estado há a presença de extensas áreas agrícolas, enquanto que na região norte há extensas áreas com vegetação nativa remanescente. Por meio da análise espacial de agrupamento, considerando a porcentagem de áreas com cobertura nativa remanescente, foi obtido o mapa ilustrado na Figura 6.

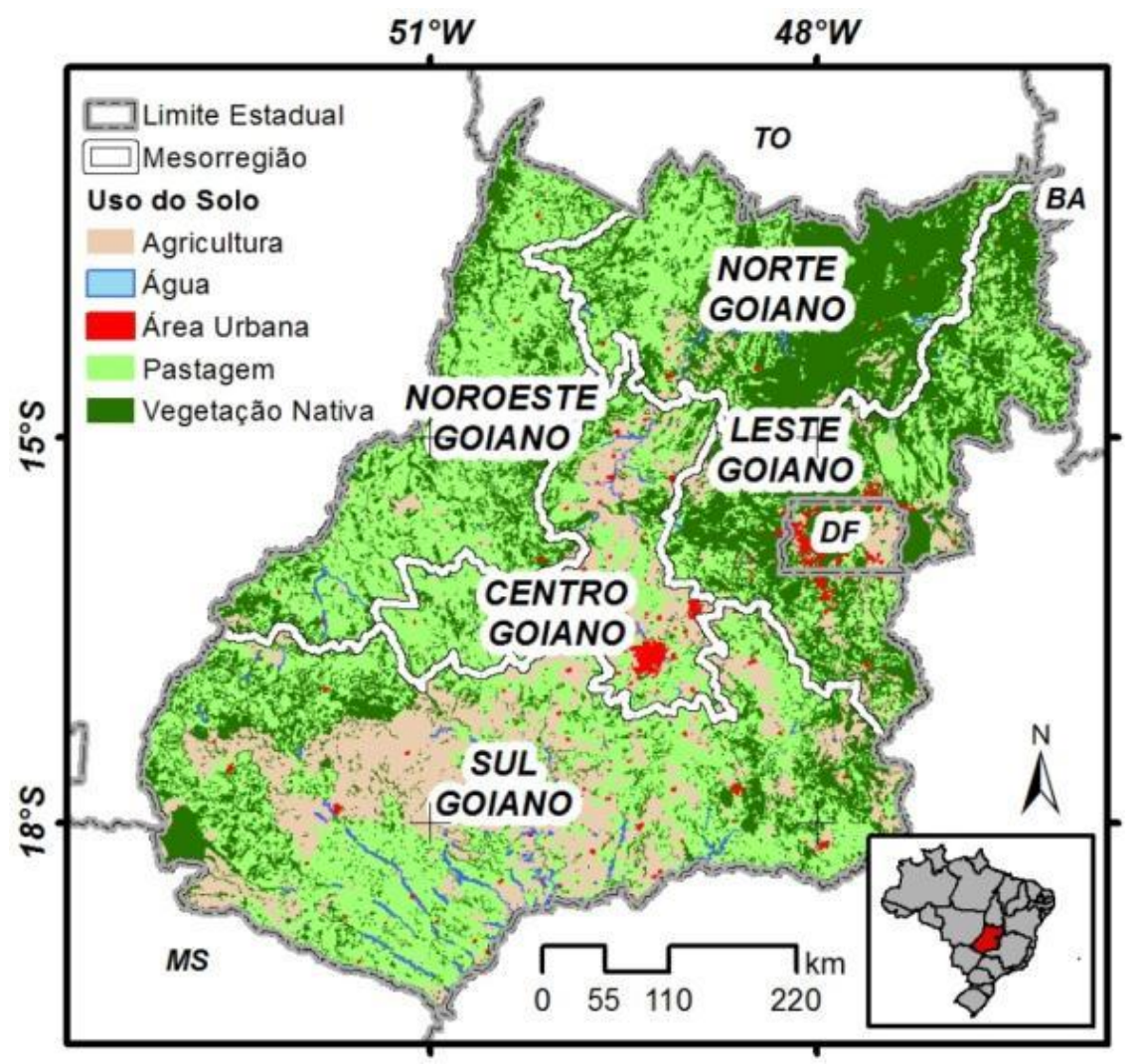

Figura 5. Mapa de uso do solo com destaque para o remanescente de cobertura vegetal. 
Conforme a Figura 6, a análise de agrupamento dos municípios, considerando a cobertura vegetal nativa remanescente, mostra que no extremo norte de Goiás se concentram os municípios com maiores reservas de vegetação. Na região central, e parte da região sul do Estado, situam-se os municípios com maiores áreas desmatadas ou desflorestadas. Finalmente, na região oeste, parte da região central e sul do estado de Goiás, concentram-se aqueles que apresentam desigualdade em relação a quantidade de cobertura vegetal nativa.

Avaliando o IDH médio em cada agrupamento, observou-se nos municípios mais preservados um IDH-médio de 0,691. Por seu turno, nas áreas com índice mediano de preservação, o IDH-médio é um pouco maior, ou seja, de 0,735. Finalmente, na região com municípios menos preservados, o IDH-médio encontrado foi de 0,747 , ou seja, o maior do Estado.

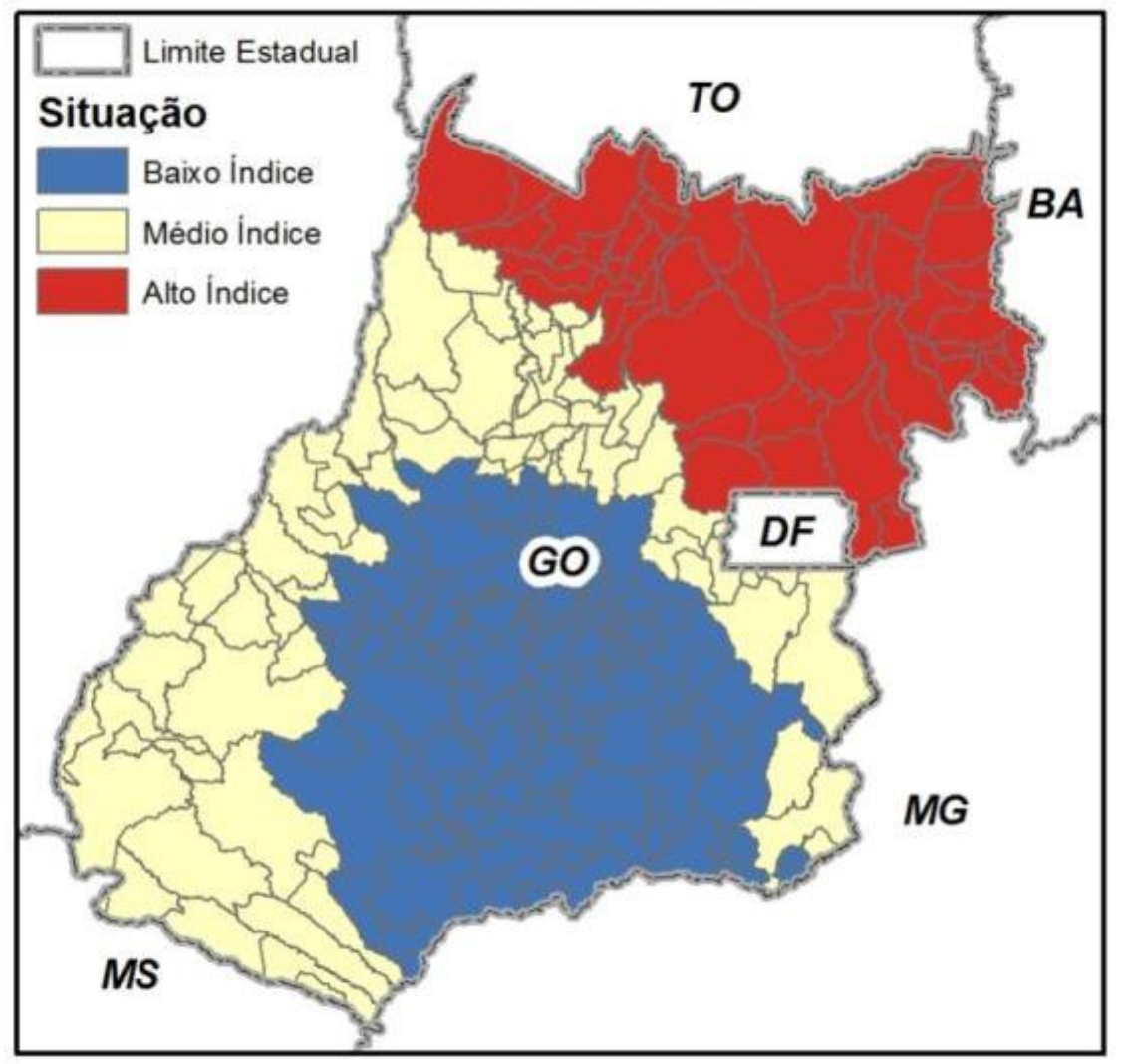

Figura 6. Mapa dos grupos dos municípios com índices de cobertura vegetal remanescentes similares no estado de Goiás, Brasil.

Nas Figuras 7, 8 e 9 apresentam-se os valores médios mensais nos anos de 2005 a 2009 dos parâmetros: cor aparente, turbidez e E. coli de 140 mananciais que abastecem os municípios atendidos pela SANEAGO. Para estes parâmetros, nota-se que a mesorregião Centro Goiano apresenta valores um pouco superiores, enquanto que o Norte Goiano possui valores mais baixos, para quase todos os meses do ano. Ao se confrontar estes dados com a Figura 5, observa-se que o Norte Goiano é a região mais preservada, e que, portanto, apresentou, para os parâmetros analisados, melhor qualidade da água natural. Já o Centro Goiano, além de possuir pouco remanescente vegetal, agrega grandes centros urbanos, com grande alteração do uso do solo e com bacias bem degradadas.

Ainda, nas Figuras 7, 8 e 9, nota-se uma variação temporal nas concentrações dos parâmetros analisados, influenciada fortemente pela precipitação, que no estado de Goiás ocorrem primordialmente os meses de novembro a abril. Os meses mais chuvosos 
coincidiram com a elevação dos valores das variáveis analisadas durante os cinco anos analisados.

Observa-se na Figura 8 que nos meses de estiagem, de março a outubro, os valores de turbidez não ultrapassam o valor de 40 UNT, limite para classificação do curso d'água como Classe I, segundo a portaria CONAMA 357/2005. Valor este superado nos meses mais chuvosos, para quase a totalidade das mesorregiões. Entretanto, estes valores não ultrapassaram em nenhuma situação o valor de 100 UNT, limite para classificação do curso d'água como Classe II. Para a variável coliforme fecal, a mesma portaria fixa o valor máximo de $10^{3} \mathrm{NMP}$ por $100 \mathrm{~m} \mathrm{~L}^{-1}$ para cursos d'água Classe 2 . Utilizando este limite para a variável E. coli, possibilidade permitida na CONAMA 357/2005, observa-se que praticamente todas as mesorregiões do estado de Goiás obtiveram valores superiores a este, com exceção do Norte Goiano, região que possui maior remanecente de vegetação nativa. Não se observam alterações consistentes dos valores destes parâmetros em escala anual ( $p>0,05)$. Assim, para o mês de janeiro, por exemplo, não se nota tendência de aumento ou redução dos valores de concentração, no intervalo de tempo analisado, 2005 a 2009.

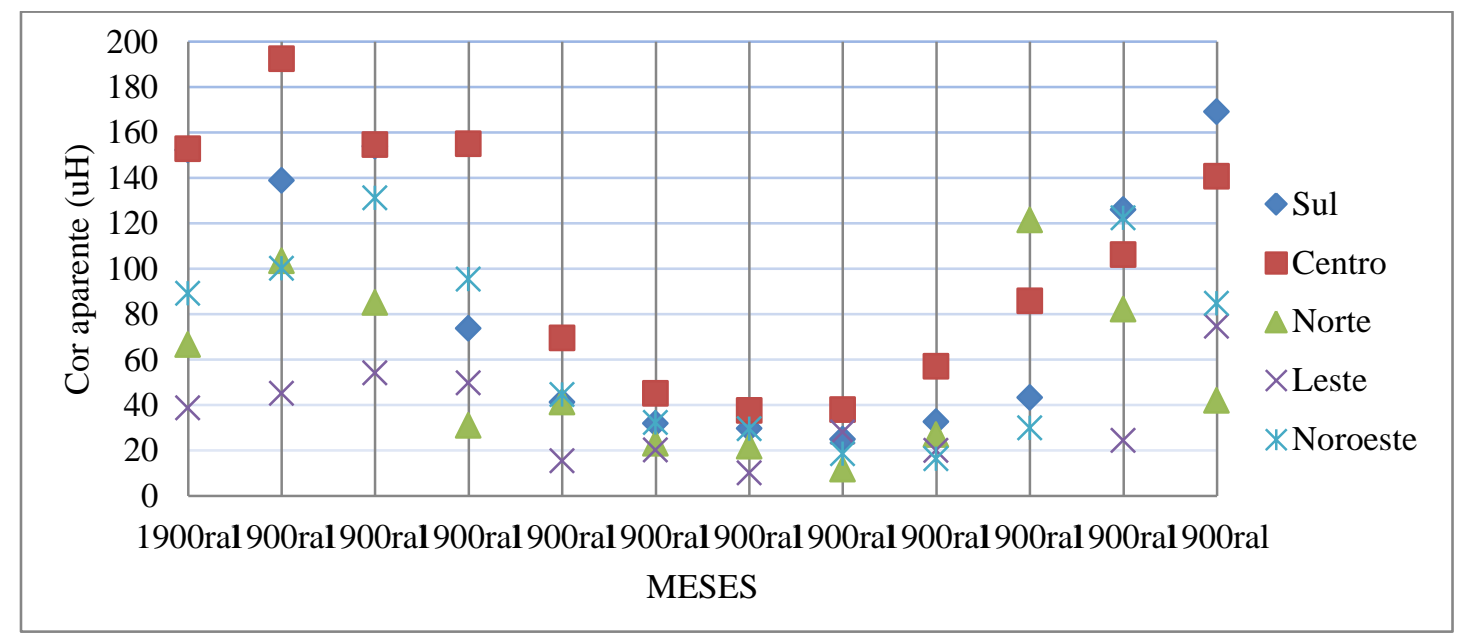

Figura 7. Variação temporal da cor aparente entre 2005 a 2009 para as mesorregiões goianas.

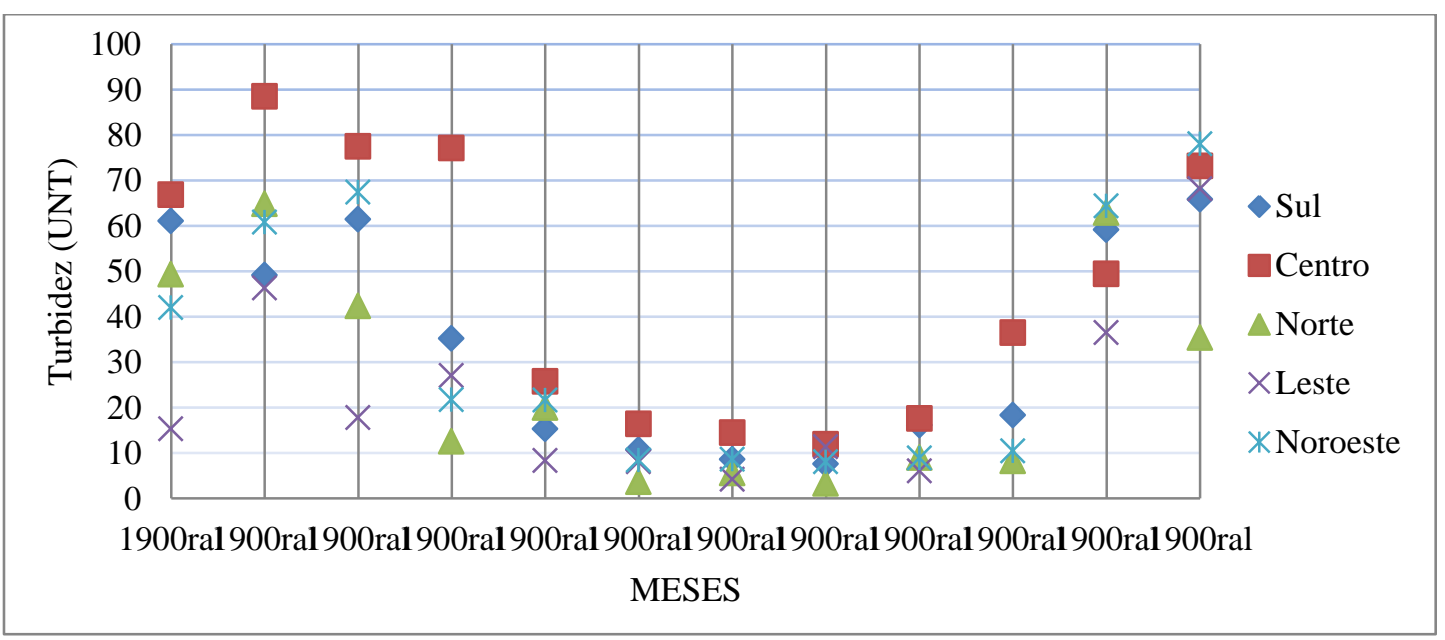

Figura 8. Variação temporal da turbidez entre 2005 a 2009 para as mesorregiões goianas. 


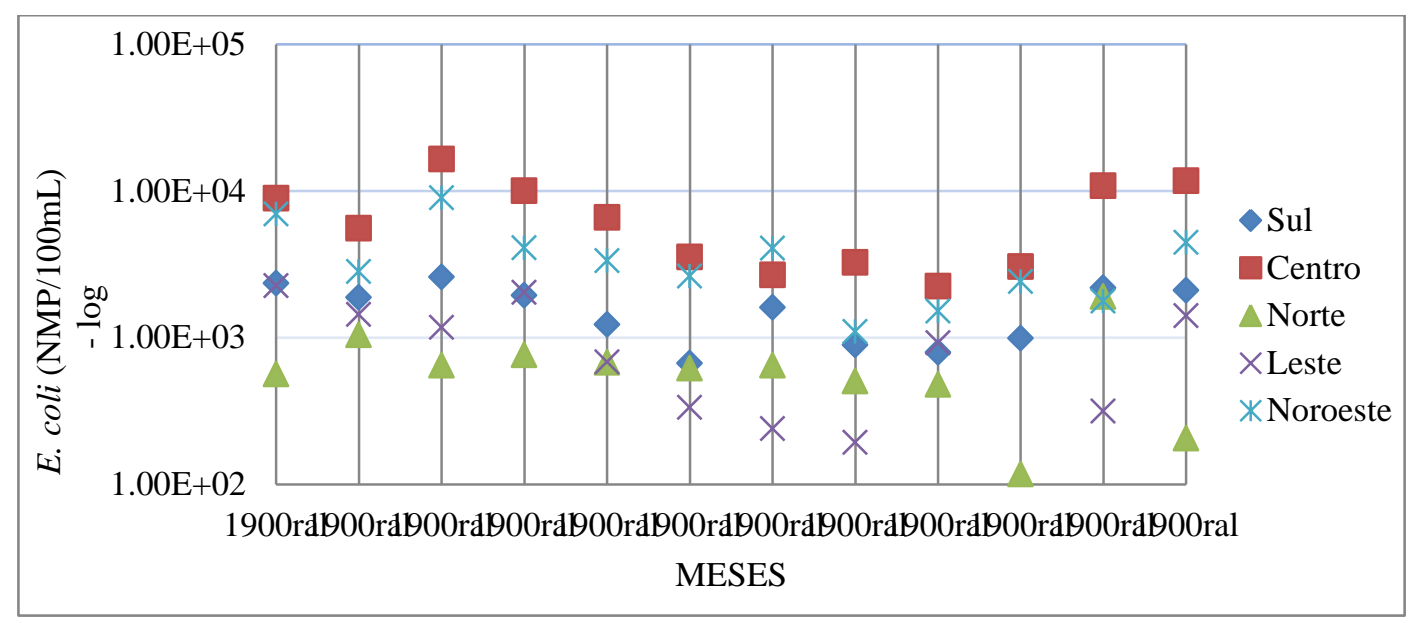

Figura 9. Variação temporal da E. coli entre 2005 a 2009 para as mesorregiões goianas.

\section{CONCLUSÃO}

Houve acréscimo significante de $99,8 \%$ na quantidade de domicílios atendidos por saneamento, de maneira adequada, no estado de Goiás, entre os anos de 2000 e 2010. A região sul do estado de Goiás concentra os municípios mais atendidos por saneamento, enquanto que as regiões norte e central concentram os municípios que menos dispõem desse tipo de serviço.

$\mathrm{Na}$ região central do Estado estão os municípios onde ocorre grande desigualdade em relação à oferta de saneamento adequado aos domicílios.

Os municípios que integram a região em que existe maior quantidade de domicílios com saneamento adequado, também possuem maiores IDH.

Nas regiões com municípios mais desmatados, e que de modo geral contam com maiores serviços de saneamento, o IDH-médio foi superior.

O Norte Goiano é a região que possui maior extensão de remanescente vegetal, e apresentou, assim como o Leste Goiano, os melhores valores para os parâmetros cor aparente, turbidez e E. coli. Já o Centro Goiano, além de possuir pouco remanescente vegetal, agrega grandes centros urbanos, com grande alteração do uso do solo e com bacias bem degradadas, apresentou valores piores.

Não se observou alteração significativa de valores de cor aparente, turbidez e E. coli, entre os anos de 2005 a 2009, para cada mês avaliado.

Quanto à variação temporal, as concentrações dos variáveis analisadas foram influenciadas fortemente pelo período chuvoso.

\section{AGRADECIMENTOS}

Os autores agradecem à Fundação de Amparo à Pesquisa do Estado de Goiás (FAPEG) pelo suporte financeiro por meio do projeto da chamada 05/2012.

\section{REFERÊNCIAS}

AMERICAN PUBLIC HEALTH ASSOCIATION - APHA; WATER WORKS ASSOCIATION - AWWA; WATER ENVIRONMENT FEDERATION - WEF. Standard methods for the examination of water and wastewater. 21th ed. Washington, 2005. 
BONNET, B. R. P.; FERREIRA, L. G.; LOBO, F. C. Relações entre qualidade da água e uso do solo em Goiás: uma análise à escala da bacia hidrográfica. Revista Árvore, v. 32, n. 2, 2008. http://dx.doi.org/10.1590/S0100-67622008000200014

BOYER, E. W.; GOODALE, C. L.; JAWORSKI, N. A.; HOWARTH, R. W. Anthropogenic nitrogen sources and relationships to riverine nitrogen export in the northeastern U.S.A. Biogeochemistry, v. 57/58, p. 137-169, 2002. http://dx.doi.org/10.1023/A\%3A1015709302073

BRASIL. Minstério das Cidades. Sistema Nacional de Informações sobre Saneamento. Brasília, 1996.

BRISCOE, J. Evaluating water supply and other health programs: short-run vs long-run mortality effects. Public Health, v. 99, n. 3, p.142-145, 1985. http://dx.doi.org/10.1016/S0033-3506(85)80103-7

HUTTON, G.; HALLER, L. Evaluation of the costs and benefits of water and sanitation improvements at the global level. Genebra: WHO, 2004.

INSTITUTO BRASILEIRO DE GEOGRAFIA E ESTATÍSTICA - IBGE. Coordenação de Geografia. Atlas de saneamento 2011. Rio de Janeiro, 2011. Disponível em: http://www.ibge.gov.br/home/estatistica/populacao/atlas_saneamento/default_zip.shtm. Acesso em: 09 set. 2015.

LIBÂNIO, P. A. C.; CHERNICHARO, C. A. de L.; NASCIMENTO, N. de O. The water quality dimension: an evaluation of the relationship between social, water availability, water services and public health indicators. Engenharia Sanitária e Ambiental, v. 10, n. 3, 2005. http://dx.doi.org/10.1590/S1413-41522005000300006

PRÜSS-ÜSTÜN, A.; BOS, R.; GORE, F.; BARTRAM, J. Safer water, better health: costs, benefits and sustainability of interventions to protect and promote health. Genebra: WHO, 2008.

PRÜSS-ÜSTÜN, A.; CORVALÁN, C. Preventing disease through healthy environments: Towards an estimate of the environmental burden of disease. Geneva: WHO, 2006.

RABElO, C. G.; FERREIRA, M. E.; ARAÚJO, J. V. G.; STONE, L. F.; SILVA, S. C.; GOMES, M. P. Influência do uso do solo na qualidade da água no bioma Cerrado: um estudo comparativo entre bacias hidrográficas no Estado de Goiás, Brasil. Revista Ambiente \& Água, v. 4, n. 2, p. 172-187, 2009. http://dx.doi.org/10.4136/ambi-agua.96

RHODES, A. L.; NEWTON, R. M.; PUFALL, A. Influences of land use on water quality of a diverse New England. Environmental Science \& Technology, v. 35, n. 18, 2001. http://dx.doi.org/10.1021/es002052u

SANO, E. E.; DAMBRÓS, L. A.; OLIVEIRA, G. C.; BRITES, R. S. Padrões de cobertura de solos do estado de Goiás. In: FERREIRA. L. G. (Org.). A encruzilhada socioambiental - biodiversidade, economia e sustentabilidade no cerrado. Goiânia: Editora da UFG, 2008.

STOCKHOLM INTERNATIONAL WATER INSTITUTE - SIWI; WORLD HEALTH ORGANIZATION - WHO. Making water part of economic development: the economic benefits of improved water management and services. Stockholm, 2005. 
TOLEDO, L. G.; NICOLELLA, G. Índice de qualidade de água em microbacia sob uso agrícola e urbano. Scientia Agricola, v. 59, n. 1, p. 181-186, 2002. http://dx.doi.org/10.1590/S0103-90162002000100026

WALTON, R. S.; HUNTER, H. M. Isolating the water quality responses of multiple land uses from stream monitoring data through model calibration. Journal of Hydrology, v. 378, p. 29-45, 2009. http://dx.doi.org/10.1016/j.jhydrol.2009.09.004

WALTON, R. S.; HUNTER, H. M. Land-use effects on fluxes of suspended sediment, nitrogen and phosphorus from a river catchment of the Great Barrier Reef, Australia. Journal of Hydrology, v. 356, p. 131-146, 2008.

http://dx.doi.org/10.1016/j.jhydrol.2008.04.003 